\title{
Pathologic and prognostic impacts of FGFR2 amplification in gastric cancer: a meta-analysis and systemic review
}

\author{
Hyeong Su Kim ${ }^{1}$, Jung Han Kim ${ }^{\circledR}$, Hyun Joo Jang ${ }^{2^{\bowtie}}$ \\ 1. Division of Hemato-Oncology, Department of Internal Medicine, Kangnam Sacred-Heart Hospital, Hallym University Medical Center, Hallym University \\ College of Medicine, Seoul, Republic of Korea \\ 2. Division of Gastroenterology, Department of Internal Medicine, Dongtan Sacred-Heart Hospital, Hallym University Medical Center, Hallym University \\ College of Medicine, Hwasung, Republic of Korea
}

$\square$ Corresponding authors: Jung Han Kim and Hyun Joo Jang. Department of Internal Medicine, Hallym University Medical Center, Hallym University College of Medicine, Seoul, Republic of Korea. E-mail: harricil@hallym.or.kr (JHK), jhj1229@hallym.or.kr (HJJ)

(C) Ivyspring International Publisher. This is an open access article distributed under the terms of the Creative Commons Attribution (CC BY-NC) license (https://creativecommons.org/licenses/by-nc/4.0/). See http://ivyspring.com/terms for full terms and conditions.

Received: 2018.08.13; Accepted: 2019.04.12; Published: 2019.06.02

\begin{abstract}
Fibroblast growth factor receptor-2 (FGFR2) gene is amplified in up to $15 \%$ of patients with gastric cancer (GC). However, the prognostic significance of FGFR2 amplification has been controversial. This meta-analysis was conducted to evaluate the clinicopathological impacts of FGFR2 amplification in patients with GC. We performed a systematic computerized search of the electronic databases of PubMed, PMC, EMBASE, Web of Science, and Google Scholar and selected studies assessing the correlation of FGFR2 amplification with pathologic features and/or prognosis in gastric adenocarcinoma. From eight studies, 2,377 patients were included in the pooled analysis of odds ratios (ORs) with $95 \%$ confidence intervals (Cls) for pathologic findings and hazard ratios (HRs) with $95 \%$ Cls for overall survival. FGFR2 amplification was significantly associated with $\mathrm{LN}$ metastasis $(\mathrm{OR}=3.93,95 \% \mathrm{Cl}: 2.22-6.96, \mathrm{p}<0.00001)$ and poorly differentiated adenocarcinoma $(\mathrm{OR}=2.36,95 \% \mathrm{Cl}$ : 1.03-5.39, $\mathrm{p}=0.04)$. In addition, patients with $\mathrm{GC}$ harboring FGFR2 amplification showed significantly worse survival $(\mathrm{HR}=2.09,95 \% \mathrm{Cl}$ : 1.68-2.59, $\mathrm{p}<$ 0.00001 ), compared with patients with FGFR2-unamplified GC. In conclusion, this meta-analysis indicates that FGFR2 amplification is an adverse prognostic factor in patients with GC.
\end{abstract}

Key words: FGFR2 amplification; gastric cancer; prognosis; meta-analysis; review

\section{Introduction}

Despite a steady decline in incidence, gastric cancer (GC) is the fifth most common cancer and the third leading cause of cancer-related death worldwide $[1,2]$. Radical surgery with or without perioperative or adjuvant treatment offers a potential chance of cure for patients with early-stage disease. However, a considerable number of patients present with advanced disease at the time of diagnosis. Moreover, more than $60 \%$ of the patients who received complete resection with curative intent develop recurrence within five years after surgery [3,4]. For patients with recurrent or metastatic diseases, systemic chemotherapy with best supportive care can prolong median overall survival (OS) from 3-4 months to approximately 10-13 months [5,6]. The combination of trastuzumab with chemotherapy in patients with HER2-positive advanced GC and the addition of ramucirumab to taxane as second-line therapy in non-selective patients with advanced GC demonstrated modest survival benefits $[7,8]$. Despite the introduction of new molecular targeted agents, however, the five-year survival rate is still less than $10 \%$; therefore, there is a critical need to identify novel therapeutic targets in order to develop more efficacious targeted agents.

The fibroblast growth factors (FGF) pathway has recently emerged as a potential therapeutic target in several types of human cancers including GC [9-12]. The FGF signaling pathway regulates a variety of cellular functions including cell proliferation, 
migration, and differentiation [12,13]. The FGFR2 gene is located on chromosome 10q26 and functions as FGF receptor (FGFR). The genetic alterations of FGFR2 reportedly enhance downstream signaling and are associated with cancer development and progression [13-15]. In preclinical models of GC, FGFR2 amplification was associated with increased proliferation and survival of tumor cells and conferred sensitivity to selective molecular agents targeting this pathway $[9,16]$. Therefore, FGFR2 amplification has been proposed as a potential treatment target and predictive biomarker for small molecule tyrosine kinase inhibitors (TKIs) or monoclonal antibodies to FGFR2 [9-11,17].

FGFR2 amplification has been reported in up to $15 \%$ of patients with GC [18-26]. Several clinical studies investigated the clinicopathological features of FGFR2-amplified GC and found that FGFR2 amplification was correlated with lymphatic invasion $[19,24]$ or worse prognosis [19-21,24]. However, the data are limited with a small number of patients with FGFR2-amplified GC, and other studies have failed to demonstrate the prognostic role of FGFR2 amplification as an independent predictor in patients with advanced GC $[23,26]$. Therefore, we performed a meta-analysis to evaluate the pathologic and prognostic impacts of FGFR2 amplification in patients with GC.

\section{Materials and Methods}

\section{Publication search strategy}

This study was conducted according to the Preferred Reporting Items for Systematic Reviews and Meta-Analyses (PRISMA) guidelines [27]. We searched the electronic databases of PubMed, PMC, EMBASE, Web of Science, and Google Scholar (up to December 2018) to identify studies assessing the correlation of FGFR2 amplification with pathologic features and/or prognosis in gastric adenocarcinoma. The search used following keywords variably combined: "fibroblast growth factor receptor 2" or "FGFR2" AND "gastric cancer" or "stomach cancer".

\section{Inclusion criteria}

Eligible studies should meet the following inclusion criteria: (i) clinical trials and prospective or retrospective cohort studies investigating the correlation of FGFR2 amplification with pathologic features and/or overall survival (OS) in patients with gastric adenocarcinoma, including adenocarcinoma of the esophago-gastric junction; (ii) the use of adequate detection methods including fluorescence in situ hybridization (FISH) or real-time quantitative polymerase chain reaction (qPCR); (iii) results providing sufficient data for odds ratio (OR) with 95\% confidence intervals (CI) for pathologic findings or hazard ratio (HR) along with 95\% CI for OS; (iv) publication only in peer-reviewed journals; and (v) articles written in English. If the articles did not accord with any of these inclusion criteria, they would be excluded from the analysis.

\section{Data extraction}

All eligible studies were independently selected by two researchers (Kim HS and Jang HJ). The following data were extracted: first author, year of publication, country, study period, sample size, stage, detecting methods and cut-off values for FGFR2 amplification, data for estimating ORs with their 95\% CIs for pathologic features [tumor depth, lymph node (LN) metastasis, and differentiation], and HR with its $95 \%$ CI for OS. If studies included cohorts of different ethnic populations, the data were collected separately to be recognized as independent results. When both univariate and multivariate analysis were performed to get the HR for survival, the data from multivariate analysis were extracted preferentially.

\section{Quality assessment}

The methodological quality of included studies was scored based on the Newcastle-Ottawa System (NOS) [28]. The scores range from 0 to 9 and studies with a score $\geq 6$ were considered to be high quality.

\section{Statistical analysis}

The survival outcomes were expressed as time-to-event HRs with 95\% CI. The strength of the correlation of pathological features was shown as ORs with 95\% CIs. These statistical values were derived directly from the primary publications. When papers did not provide the ORs and HRs with their 95\% CIs, the Engauge Digitizer was used to estimate them from the available data and Kaplan-Meier curves, respectively. The RevMan version 5.3 software (Cochrane Collaboration, Copenhagen, Denmark) was utilized to combine the ORs or HRs along with their 95\% CIs. The heterogeneity across studies was estimated by the $\mathrm{Q}$ statistics and $\mathrm{I}^{2}$ inconsistency test. The Mantel-Haenszel method (fixed-effect model) was used for pooling homogeneous outcomes ( $p \geq 0.1$ and $\left.\mathrm{I}^{2} \leq 50 \%\right)$, and the DerSimonian-Laird method (random-effects model) was selected when significant heterogeneity was observed ( $\mathrm{p}<0.1$ or $\mathrm{I}^{2}>50 \%$ ).

Outcomes are provided as forest plots with diamonds representing the estimate of the pooled effect. The line of no effect is number one for binary outcomes, which depicts statistical significance if not crossed by the diamond [29]. The OR or HR $>1.0$ implies worse pathological features or survival for patients with FGFR2 amplified GC. 
Publication bias was visually evaluated by the funnel plots and then quantified by the Begg's test and Egger's test $[30,31]$. Two-sided $p$ was considered statistically significant if it was less than 0.05 .

\section{Results}

\section{Results of search}

A total of 162 potentially relevant articles were initially found, but 142 of them were excluded after careful screening of the titles and abstracts. Of the remaining 20 potentially eligible studies, 12 were further excluded by the inclusion criteria. Finally, 8 studies were included in the meta-analysis [19-26]. Figure 1 shows the search flow diagram of this meta-analysis.

\section{Characteristics of the included studies}

Table 1 summarizes the main characteristics and pathological findings of the eight included studies. The studies were performed retrospectively and published between 2012 and 2017. Two studies [23,26] involved only patients who had received chemotherapy for advanced or metastatic GC. The studies were conducted mostly in Asian populations (from Korea, Japan, China, and Singapore), and one consisted of 3 cohorts from the United Kingdom (UK), China, and Korea [24]. The NOS scores were more than 7 in all the studies, indicating a good methodological quality.

FISH or real-time qPCR was used to detect FGFR2 amplification. Most studies using FISH

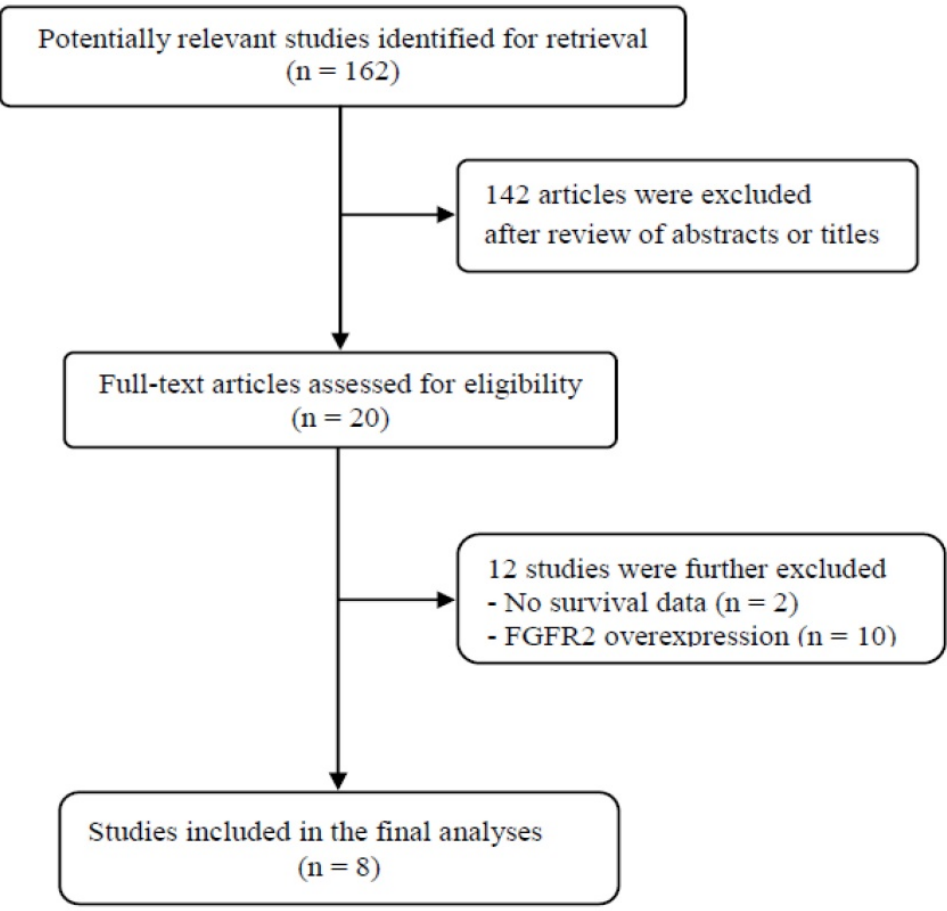

Figure 1. Flow diagram of search process adopted FGFR2/CEP10 $\geq 2$ as cut-off for FGFR2 amplification [19-24]. Frequencies of FGFR2 amplification in the included studies ranged from $1.8 \%$ [21] to $15 \%$ [25], depending on the technique used and the cut-point for positivity. Three studies reported FGFR2 amplification as a potential adverse prognostic factor [19-21]. In the study with 3 cohorts, FGFR2 amplification showed a significant prognostic role only in the UK cohort [24]. However, the remaining four studies failed to observe statistically significant impact of FGFR2 amplification on survival in the univariate $[22,25]$ or multivariate analysis $[23$, 26].

\section{Impact of FGFR2 amplification on pathologic features}

From five studies [19,20,22,24,15], 1,818 patients were included in the pooling of ORs with $95 \%$ CIs for the depth of tumor invasion ( $\mathrm{pT})$. There was no significant heterogeneity among studies $\left(\mathrm{X}^{2}=2.72, \mathrm{p}=\right.$ $\left.0.61, \mathrm{I}^{2}=0 \%\right)$. FGFR2 amplification was not significantly associated with tumor invasion (pT3-4) $(\mathrm{OR}=1.36,95 \% \mathrm{CI}: 0.90-2.05, \mathrm{p}=0.14$, fixed-effect model) (Figure 2A).

From five studies [19,22-25], 1,612 patients were analyzed for the impact of FGFR2 amplification on the LN metastasis. There was no substantial heterogeneity across the studies $\left(X^{2}=4.77, p=0.31\right.$, $\mathrm{I}^{2}$ $=16 \%)$. Compared with tumors without FGFR2 amplification, FGFR2-amplified GCs exhibited higher rate of LN metastasis (OR $=3.93,95 \%$ CI: 2.22-6.96, $\mathrm{p}<$ 0.00001, fixed-effect model) (Figure 2B).

From five studies [19,22,24-26], 1,878 patients were included in combining the ORs for tumor differentiation. The random-effects model was selected for pooling heterogeneous outcomes $\left(X^{2}=9.34, p=0.05, I^{2}=57 \%\right)$. FGFR2 amplification were significantly associated with differentiation (poorly differentiated or undifferentiated adenocarcinoma) in GCs (OR $=2.36,95 \%$ CI: 1.03-5.39, $\mathrm{p}=0.04)$ (Figure 2C).

\section{Impact of FGFR2 amplification on survival}

From the eight studies, a total of 2,377 patients were included in the meta-analysis of HRs for OS. Compared with patients with FGFR2-unamplified GC, patients with GC harboring FGFR2 amplification showed significantly worse survival $(\mathrm{HR}=2.09,95 \%$ CI: 1.68-2.59, p < 0.00001) (Figure 3A). The fixed-effect model was used because there was no significant heterogeneity among studies $\left(\mathrm{X}^{2}\right.$ $\left.=4.31, \mathrm{p}=0.89, \mathrm{I}^{2}=0 \%\right)$. 
Table 1. Summary of the eight included studies

\begin{tabular}{|c|c|c|c|c|c|c|c|c|c|c|c|}
\hline $\begin{array}{l}\text { First author } \\
\text { (year) [ref.] }\end{array}$ & Country & $\begin{array}{l}\text { No. of } \\
\text { pts }\end{array}$ & $\begin{array}{l}\text { Inclusion } \\
\text { period }\end{array}$ & $\begin{array}{l}\text { TNM } \\
\text { stage }\end{array}$ & Methods & Cut-off & $\begin{array}{l}\text { FGFR2 } \\
\text { amplification } \\
(\%)\end{array}$ & $\begin{array}{l}\text { Tumor depth } \\
\text { (pT3-4) } \\
\text { (yes : no) }\end{array}$ & $\begin{array}{l}\text { LN metastasis } \\
\text { (yes : no) }\end{array}$ & $\begin{array}{l}\text { Differentiation } \\
\text { (PD or UD) } \\
\text { (yes : no) }\end{array}$ & $\begin{array}{l}\text { NOS } \\
\text { score }\end{array}$ \\
\hline $\begin{array}{l}\text { Jung } \\
\text { (2012) [19] }\end{array}$ & Korea & 313 & 2004 & I-IV & FISH & FGFR2/CEP10 > 2 & $14(4.5 \%)$ & $\begin{array}{l}10(71 \%): 159(53 \%) \\
p=0.032\end{array}$ & $\begin{array}{l}12(86 \%): 168(56 \%) \\
p=0.038\end{array}$ & $\begin{array}{l}9(64 \%): 160(54 \%) \\
p=0.452\end{array}$ & 8 \\
\hline $\begin{array}{l}\text { Matsumoto } \\
(2012)[20]\end{array}$ & Japan & 267 & 1996-2006 & I-IV & $\begin{array}{l}\text { RT-qPCR } \\
\text { or FISH }\end{array}$ & $\begin{array}{l}\geq 5 \text { copies or } \\
\text { FGFR2/CEP10 } \geq 2\end{array}$ & $11(4.1 \%)$ & $\begin{array}{l}11(100 \%): 198 \\
(77 \%) \\
p=0.16\end{array}$ & NA & NA & 8 \\
\hline $\begin{array}{l}\text { Betts } \\
(2014) \text { [21] }\end{array}$ & UK & 171 & 1995-2004 & I-IV & FISH & FGFR2/CEN10 $\geq 2$ & $3(1.8 \%)$ & NA & NA & NA & 8 \\
\hline $\begin{array}{l}\text { Das } \\
(2014)[22]\end{array}$ & Singapore & 137 & $1997-2012$ & I-IV & FISH & FGFR2/CEN10 $\geq 2$ & $10(7.3 \%)$ & $4(50 \%): 42(46 \%)$ & $7(88 \%): 67(73 \%)$ & $8(89 \%): 58(64 \%)$ & 7 \\
\hline $\begin{array}{l}\text { Shoji } \\
\text { (2015) [23] }\end{array}$ & Japan & 61 & 2005-2013 & IV & FISH & $\begin{array}{l}\text { FGFR2/CEP10 }>2 \\
\text { or tight gene } \\
\text { clusters in }>10 \% \text { of } \\
\text { tumor cells }\end{array}$ & $7(11.5 \%)$ & NA & $\begin{array}{l}7(100 \%): 31(57 \%) \\
p=0.04\end{array}$ & NA & 7 \\
\hline $\begin{array}{l}\text { Su } \\
(2014)[24]\end{array}$ & $\begin{array}{l}\text { China, } \\
\text { Korea, } \\
\text { UK }\end{array}$ & $\begin{array}{l}197 \\
356 \\
408\end{array}$ & $\begin{array}{l}2007-2010 \\
1996 \\
1970-2004\end{array}$ & I-IV & FISH & $\begin{array}{l}\text { FGFR2/CEP10 } \geq 2 \\
\text { or gene clusters in }> \\
10 \% \text { of tumor cells }\end{array}$ & $\begin{array}{l}9(4.6 \%) \\
15(4.2 \%) \\
30(7.4 \%)\end{array}$ & $\begin{array}{l}29(54 \%): 475(52 \%) \\
p=0.567\end{array}$ & $\begin{array}{l}50(93 \%): 602(66 \%) \\
p=0.000012\end{array}$ & $\begin{array}{l}43(80 \%): 525(58 \%) \\
p=0.0176\end{array}$ & 8 \\
\hline $\begin{array}{l}\text { Tokunaga } \\
\text { (2016) [25] }\end{array}$ & Japan & 140 & 2000-2014 & I-IV & RT-qPCR & $>3$ copies & $21(15 \%)$ & $\begin{array}{l}13(62 \%): 63(53 \%) \\
p=0.689\end{array}$ & $\begin{array}{l}12(57 \%): 53(45 \%) \\
p=0.286\end{array}$ & $\begin{array}{l}4(19 \%): 39(33 \%) \\
p=0.305\end{array}$ & 7 \\
\hline $\begin{array}{l}\text { Seo } \\
(2017)[26]\end{array}$ & Korea & 327 & 2006-2014 & IIIB-IV & RT-qPCR & $\geq 8$ copies & $16(4.9 \%)$ & NA & NA & $\begin{array}{l}14(88 \%): 190(62 \%) \\
p=0.041\end{array}$ & 8 \\
\hline
\end{tabular}

A

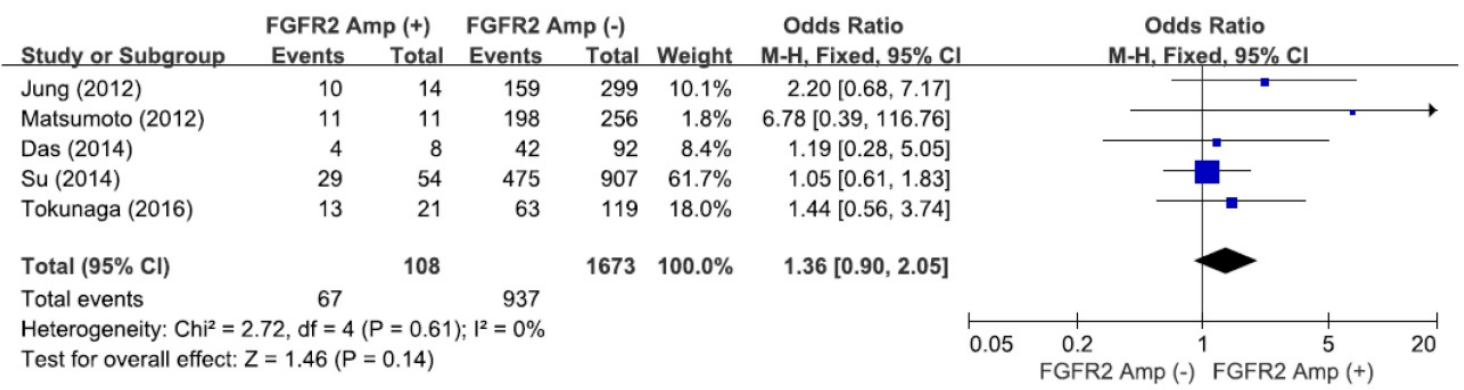

B

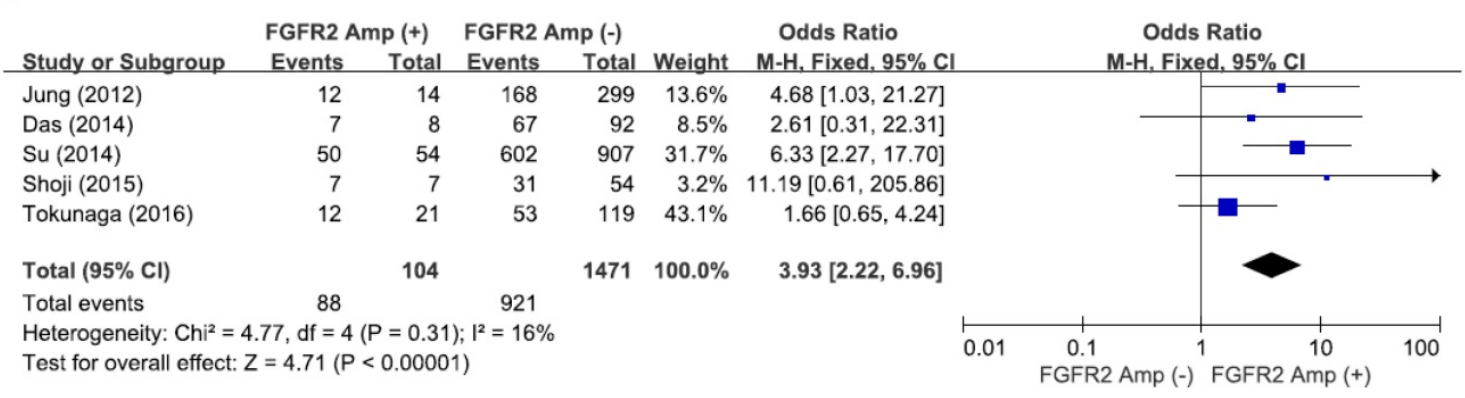

C

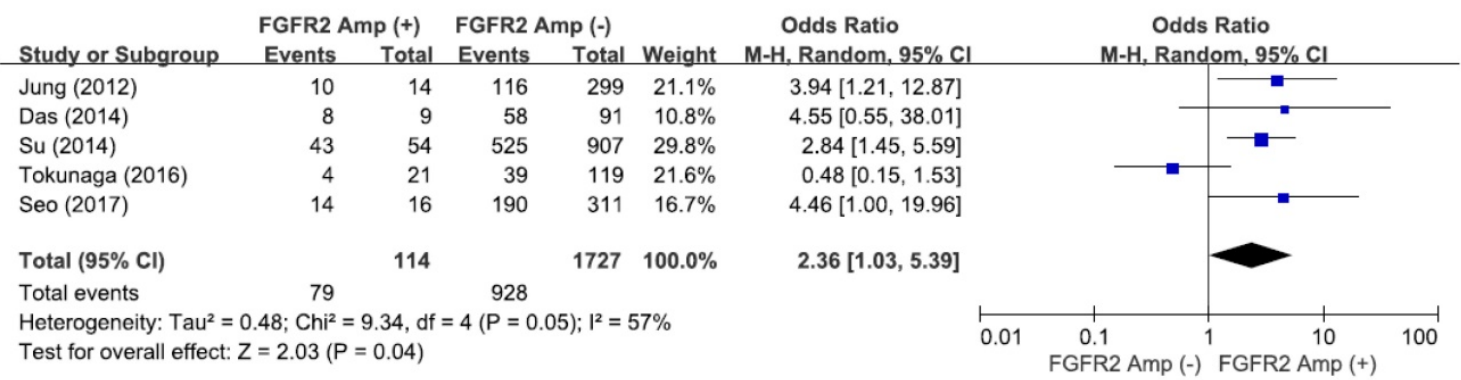

Figure 2. Forest plots of odds ratios for pT3-4 (A), LN metastasis (B), and differentiation (C). FGFR2 amplification is significantly associated with LN metastasis and differentiation. 
A

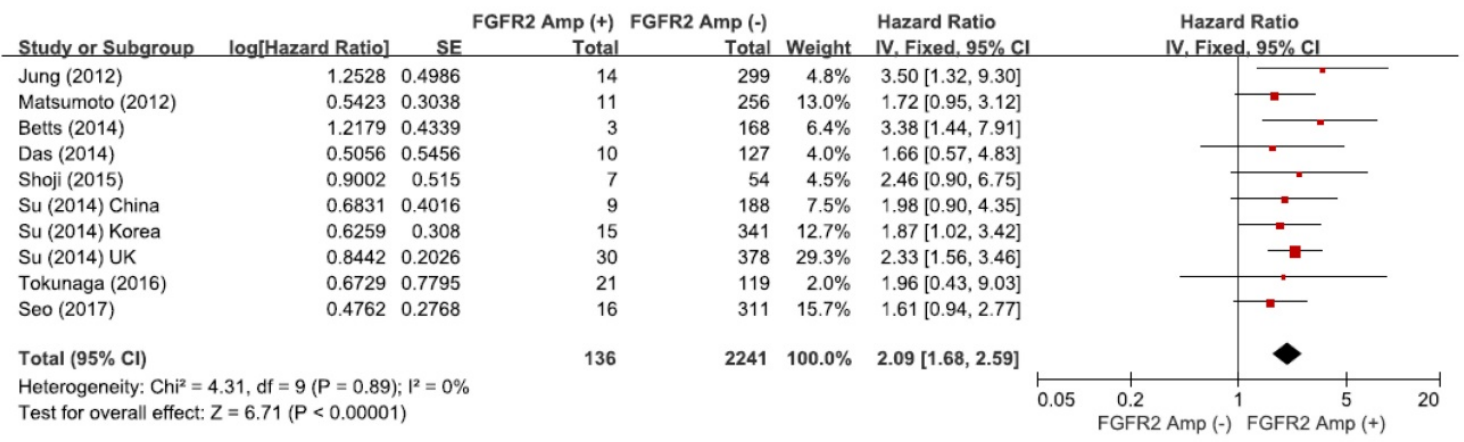

B

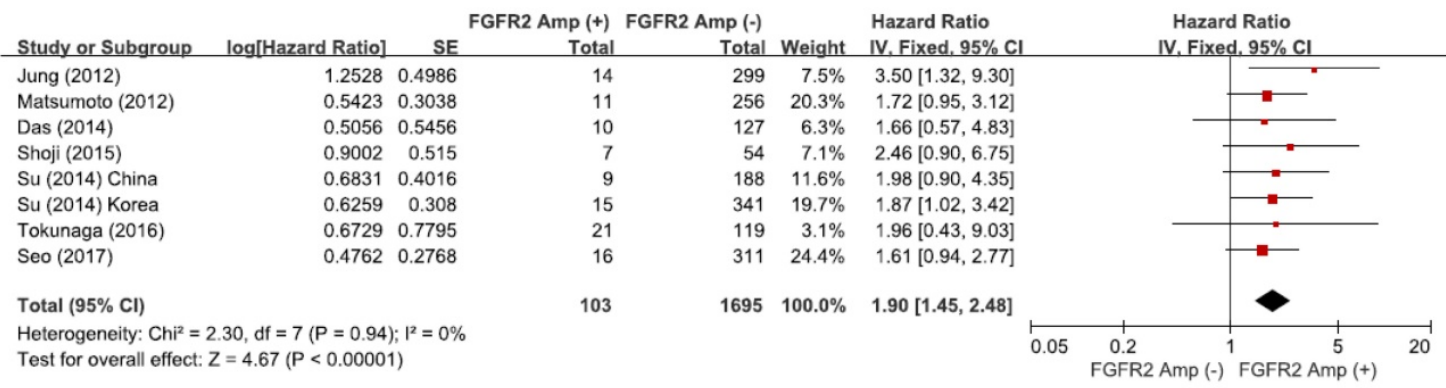

C

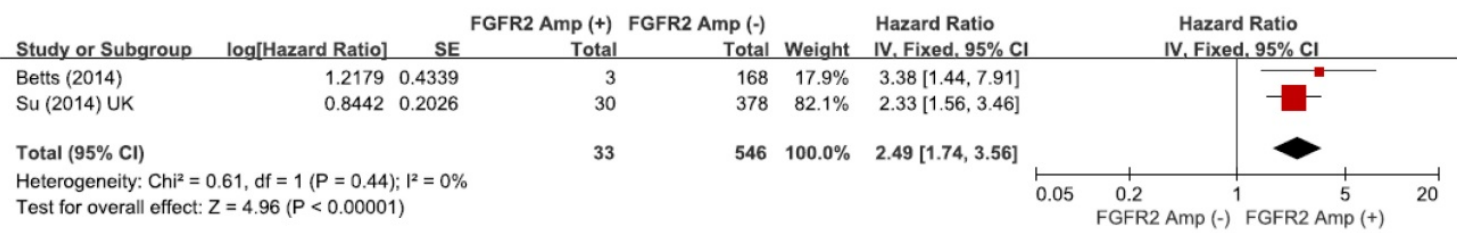

Figure 3. Forest plots of hazard ratios for survival: (A) overall, (B) Asian, and (C) European (UK). FGFR2 amplification was significantly associated with worse survival, regardless of ethnicity.

The subgroup-analysis according to the ethnicity showed that there was a significant correlation between FGFR2 amplification and survival in both Asian $(\mathrm{HR}=1.90,95 \% \mathrm{CI}: 1.45-2.48, \mathrm{p}<0.00001$, fixed-effect model, Figure 3B) and European patients (HR $=2.49,95 \%$ CI: 1.74-3.56, $\mathrm{p}<0.00001$, fixed-effect model, Figure 3C).

\section{Publication bias}

We did not perform publication bias tests for pathologic findings because a small number of studies were included in the analyses. Begg's funnel plot and Egger's test indicated no evidence of substantial publication bias for OS (Begg's $p=0.210$, Egger's $p=$ 0.620) (Figure 4).

\section{Discussion}

The FGFR signaling pathway has recently emerged as a potential molecular target for the treatment of advanced GC. However, the prognostic impact of FGFR2 amplification is still controversial. In the current meta-analysis, we evaluated the pathologic and prognostic significance of FGFR2 amplification in patients with GC. To our knowledge, this is the first meta-analysis to provide an in-depth analysis of FGFR2 amplification in relation with prognosis of patients only with GC.

The FGF/FGFR signaling pathway has been involved in tumorigenesis and progression in human cancers including multiple myeloma, cancers of the stomach, breast, bladder, prostate, and endometrium [32]. Mechanisms for genetic alteration of FGFR2 include gene amplification, mutations, gene fusions, or receptor overexpression. In GC, FGFR2 protein by immunohistochemistry is overexpressed in up to $40 \%$. Although FGFR2 amplification is significantly associated with FGFR2 overexpression [25], FGFR2 gene is amplified rarely in GCs [33]. In the included studies of this meta-analysis, frequencies of FGFR2 amplification varied from $1.8 \%$ [21] to $15 \%$ [25]. Notably, various laboratory methods, such as real-time qPCR, FISH, chromogenic or silver in situ hybridization, can be used for assessing FGFR2 amplification. Although FISH has been most 


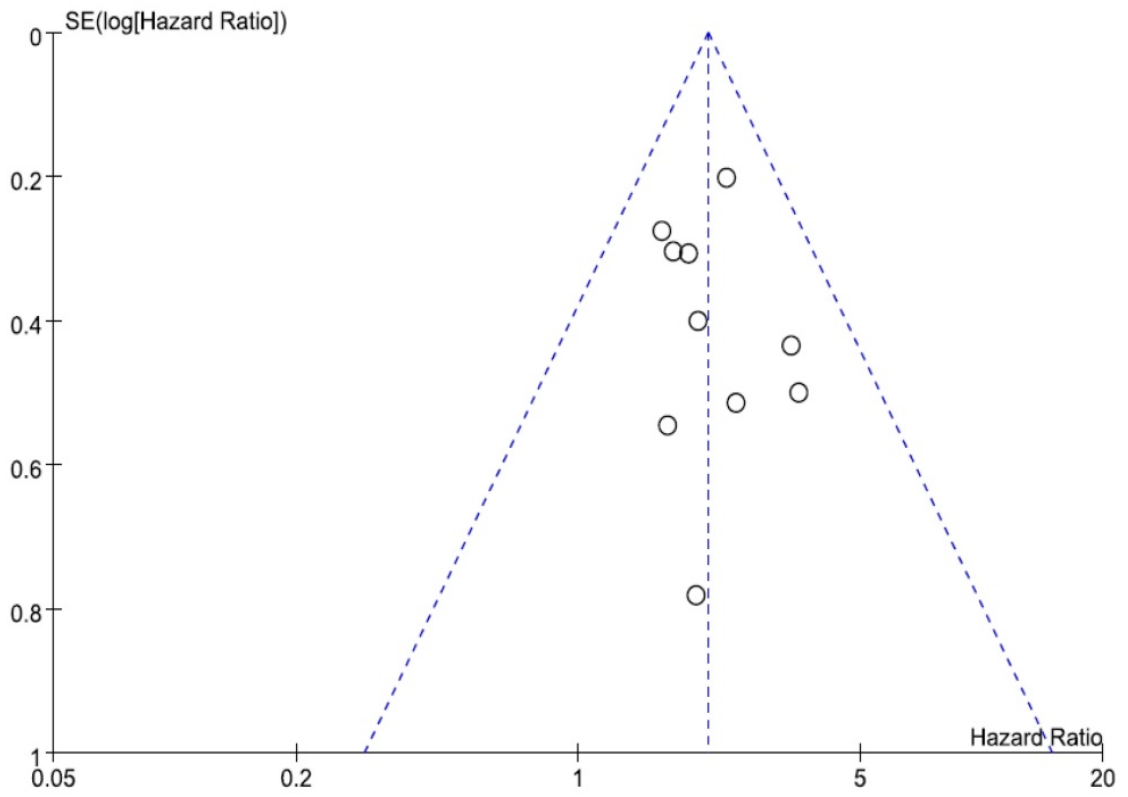

Figure 4. Funnel plot for publication bias regarding overall survival. The symmetry indicated no evidence of substantial publication bias.

commonly used, there is no consensus for the cut-off criteria to define FGFR2 amplification [33]. These differences in methodology may be the cause of the large range heterogeneity of FGFR2 positivity and the discrepancies in the prognostic role of FGFR2 amplification among studies.

The clinical significance of FGFR2 amplification or receptor overexpression has been investigated in multiple cancers [18-26,33,34]. However, their prognostic impacts in patients with GC remains controversial, as existing studies reported conflicting results with a small number of patients. There are three published papers of meta-analysis which evaluated the prognostic roles of FGFR2 gene amplification or receptor overexpression in human cancers [33-35]. Chang et al. conducted the first meta-analysis to evaluate the prognostic value of FGFR (FGFR1 and FGFR2) gene amplification in patients with different types of cancer [33]. Their results revealed that OS was significantly worse among patients with FGFR1 or FGFR2 amplification. The subgroup analysis indicated that FGFR2 amplification was associated with worse survival in patients with GC $(\mathrm{HR}=2.27,95 \%$ CI: 1.73-3.00). However, the subgroup analysis used only 3 studies, including one published in abstract from [36]. Liu et al. conducted a meta-analysis to examine the prognostic role of FGFR2 protein expression in human cancers and suggested that FGFR2 overexpression was correlated with decreased survival in most solid tumors [34]. However, they pooled together the studies evaluating the prognostic significance of not only receptor overexpression but also FGFR2 amplification (without separation between protein overexpression and gene amplification). Recently we published the results of the meta-analysis assessing the clinicopathological significance of FGFR2 overexpression in patients only with GC [35]. Tumors showing high FGFR2 expression revealed deeper invasion (pT3-4) $(\mathrm{OR}=2.63,95 \%$ CI: 1.70-4.06, $\mathrm{p}<$ $0.0001)$, higher rate of $\mathrm{LN}$ metastasis $(\mathrm{OR}=1.87,95 \% \mathrm{CI}$ : 1.31-2.67, $\mathrm{p}<0.0001)$, and more advanced stage (III-IV) (OR $=1.78$, 95\% CI: 1.07-2.96, $\mathrm{p}=0.03)$. In addition, patients with FGFR2-overexpressed GC showed worse survival, compared to patients with FGFR2-low tumor $(\mathrm{HR}=1.40,95 \%$ CI: 1.25-1.58, $\mathrm{p}<$ 0.00001) [35].

In the current study, we systematically evaluated pathological findings and survival data of 2,377 patients from the eight studies assessing FGFR2 gene amplification in GC samples [19-26]. FGFR2 amplification failed to show a significant correlation with tumor depth $(\mathrm{OR}=1.36,95 \% \mathrm{CI}$ : 0.90-2.05, $\mathrm{p}=$ 0.14). However, FGFR2 amplification was significantly associated with $\mathrm{LN}$ metastasis (OR = 3.93, 95\% CI: 2.22-6.96, p < 0.00001) and poorly differentiated or undifferentiated adenocarcinoma $(\mathrm{OR}=2.36,95 \% \mathrm{CI}: 1.03-5.39, \mathrm{p}=0.04)$. In addition, patients with FGFR2-amplified GC showed significantly worse survival $(\mathrm{HR}=2.09,95 \% \mathrm{CI}$ : $1.68-2.59, \mathrm{p}<0.00001)$. In the study with three cohorts (UK, Chinese, and Korean) by Su et al. [24], whereas FGFR2 amplification and polysomy were associated with poor OS in the Korean (1.83 vs. 6.17 years, $\mathrm{p}=$ $0.0073)$ and UK cohorts ( 0.45 vs. 1.9 years, $p<0.0001)$, FGFR2 amplification was an independent marker of poor survival only in the UK cohort $(\mathrm{HR}=2.33,95 \%$ CI: 1.56-3.46, $\mathrm{p}=0.0002)$. In our study, however, the subgroup analysis according to the ethnicity revealed that the relationship between FGFR2 amplification and poor survival was significant in both Asian (HR = 1.90, 95\% CI: 1.45-2.48, p < 0.00001) and European (patients from UK) $(\mathrm{HR}=2.49,95 \% \mathrm{CI}: 1.74-3.56, \mathrm{p}<$ 0.00001). These results indicate that FGFR2 amplification is a potential biomarker of poor prognosis in GC.

There has been a strong rationale for the development of FGFR2 inhibitors in solid tumors [9-12,16,33-35]. GC cell lines harboring FGFR2 amplification are highly sensitive to FGFR2 inhibitors 
in preclinical models [9]. Therefore, FGFR2 amplification has attracted significant interest as a therapeutic target for FGFR2-amplified GC. Although several FGFR TKIs has been under active investigation, only AZ4547 has demonstrated encouraging signs of efficacy among patients with FGFR2-amplifed GC so far [37]. AZD4547 is a selective FGFR-1, 2, 3 TKI that has a potent anti-tumor activity [9,38]. AZD4547 induced rapid tumor regression in two in vivo models (SNU16 and SGC083) of GC possessing FGFR2 amplification [9]. In the randomized phase II SHINE study, however, AZD4547 failed to significant improve progression-free survival versus paclitaxel in patients with advanced GC harboring FGFR2 polysomy or gene amplification [39]. In addition, exploratory biomarker analyses revealed marked intratumoral heterogeneity of FGFR2 amplification and poor concordance between amplification/polysomy and FGFR2 mRNA expression. Therefore, the potential usefulness of FGFR2 amplification as a predictive factor for response to FGFR2 targeting therapy remains to be investigated in GC. The mechanisms that cause primary or acquired resistance to FGFR2 inhibitors in GC are unknown. One possible explanation is that other receptor tyrosine kinases (RTKs) can restore the activation of key intracellular signaling pathways despite inhibition of oncogenic kinase, leading to resistance [40]. Actually Chang et al. demonstrated that several RTKs, including EGFR, HER3, and MET, activation contributed to AZ4547 hyposensitivity in FGFR2-amplified GC cells [41]. In addition, combination of AZ4547 and cetuximab (EGFR monoclonal antibody) showed synergic growth inhibition both in vitro and in vivo. These results may provide a rationale for a combination strategy with agents targeting FGFR2 and other resistance-enriched RTKs.

Our study has several inherent limitations. First, the included studies showed considerable differences in the detection methods and cut-off criteria for FGFR2 amplification, tumor stage, treatment, and other demographic or clinicopathological data. Second, the studies were retrospectively performed and therefore might carry the biases of the retrospective design. Finally, the heterogeneity observed among studies could not be completely interpreted although the random-effects model was selected in pooling ORs for differentiation.

In conclusion, this meta-analysis and systemic review summarized the existing data on FGFR2 amplification and clinical outcomes in patients with GC. The results suggest that FGFR2 amplification is an adverse prognostic factor in GC. However, large prospective studies using standardized methods based on the homogeneous populations are warranted to validate the prognostic value of FGFR2 amplification in patients with GC. In addition, the potential usefulness of FGFR2 amplification as a predictive biomarker for response to FGFR2 inhibitors remains to be investigated.

\section{Competing Interests}

The authors have declared that no competing interest exists.

\section{References}

1. Jung KW, Won YJ, Kong HJ, Lee ES; Community of Population-Based Regional Cancer Registries. Cancer statistics in Korea: incidence, mortality, survival, and prevalence in 2015. Cancer Res Treat. 2018; 50: 303-16.

2. Ferlay J, Soerjomataram I, Dikshit R, Eser S, Mathers C, Rebelo M, et al. Cancer incidence and mortality worldwide: sources, methods and major patterns in GLOBOCAN 2012. Int J Cancer. 2015; 136: 359-86.

3. Lim DH, Kim DY, Kang MK, Kim YI, Kang WK, Park CK, et al. Patterns of failure in gastric carcinoma after D2 gastrectomy and chemoradiotherapy: a radiation oncologist's view. Br J Cancer. 2004; 91: 11-7.

4. Yoo $\mathrm{CH}$, Noh SH, Shin DW, Choi SH, Min JS. Recurrence following curative resection for gastric carcinoma. Br J Surg. 2000; 87: 236-42.

5. Wagner AD, Grothe W, Haerting J, Kleber G, Grothey A, Fleig WE. Chemotherapy in advanced gastric cancer: a systematic review and meta-analysis based on aggregate data. J Clin Oncol. 2006; 24: 2903-9.

6. Cunningham D, Starling N, Rao S, Iveson T, Nicolson M, Coxon F, Middleton G, Daniel F, Oates J, Norman AR; Upper Gastrointestinal Clinical Studies Group of the National Cancer Research Institute of the United Kingdom. Capecitabine and oxaliplatin for advanced esophagogastric cancer. N Engl J Med. 2008; 358: 36-46.

7. Bang YI, Van Cutsem E, Feyereislova A, Chung HC, Shen L, Sawaki A, et al. Trastuzumab in combination with chemotherapy versus chemotherapy alone for treatment of HER2-positive advanced gastric or gastro-oesophageal junction cancer (ToGA): a phase 3, open-label, randomised controlled trial. Lancet. 2010; 376: 687-97.

8. Wilke H, Muro K, Van Cutsem E, Oh SC, Bodoky G, Shimada Y, et al. Ramucirumab plus paclitaxel versus placebo plus paclitaxel in patients with previously treated advanced gastric or gastro-oesophageal junction adenocarcinoma (RAINBOW): a double-blind, randomised phase 3 trial. Lancet Oncol. 2014; 15: 1224-35.

9. Xie L, Su X, Zhang L, Yin X, Tang L, Zhang X, et al. FGFR2 gene amplification in gastric cancer predicts sensitivity to the selective FGFR inhibitor AZD4547. Clin Cancer Res. 2013; 19: 2572-83.

10. Nakamura K, Yashiro M, Matsuoka T, Tendo M, Shimizu T, Miwa A, et al. A novel molecular targeting compound as K-samII/FGF-R2 phosphorylation inhibitor, Ki23057, for Scirrhous gastric cancer. Gastroenterology. 2006; 131: 1530-41.

11. Bai A, Meetze K, Vo NY, Kollipara S, Mazsa EK, Winston WM, et al. GP369, an FGFR2-IIIb-specific antibody, exhibits potent antitumor activity against human cancers driven by activated FGFR2 signaling. Cancer Res. 2010; 70: 7630-9.

12. Brooks AN, Kilgour E, Smith PD. Molecular pathways: fibroblast growth factor signaling: a new therapeutic opportunity in cancer. Clin Cancer Res. 2012; 18: 1855-62.

13. Eswarakumar VP, Lax I, Schlessinger J. Cellular signaling by fibroblast growth factor receptors. Cytokine Growth Factor Rev. 2005; 16: 139-49.

14. Dailey L, Ambrosetti D, Mansukhani A, Basilico C. Mechanisms underlying differential responses to FGF signaling. Cytokine Growth Factor Rev. 2005; 16: 233-47.

15. Grose R, Dickson C. Fibroblast growth factor signaling in tumorigenesis. Cytokine Growth Factor Rev. 2005; 16: 179-86.

16. Zhao WM, Wang L, Park $\mathrm{H}$, Chhim S, Tanphanich $\mathrm{M}$, Yashiro M, et al. Monoclonal antibodies to fibroblast growth factor receptor 2 effectively inhibit growth of gastric tumor xenografts. Clin Cancer Res. 2010; 16: 5750-8.

17. Guagnano V, Kauffmann A, Wohrle S, Stamm C, Ito M, Barys L, et al. FGFR genetic alterations predict for sensitivity to NVP-BGJ398, a selective pan-FGFR inhibitor. Cancer Discov. 2012; 2: 1118-33.

18. Deng N, Goh LK, Wang H, Das K, Tao J, Tan IB, et al. A comprehensive survey of genomic alterations in gastric cancer reveals systematic patterns of molecular exclusivity and co-occurrence among distinct therapeutic targets. Gut. 2012; 61: 673-84.

19. Jung EJ, Jung EJ, Min SY, Kim MA, Kim WH. Fibroblast growth factor receptor 2 gene amplification status and its clinicopathologic significance in gastric carcinoma. Hum Pathol. 2012; 43: 1559-66.

20. Matsumoto K, Arao T, Hamaguchi T, Shimada Y, Kato K, Oda I, et al. FGFR2 gene amplification and clinicopathological features in gastric cancer. $\mathrm{Br} \mathrm{J}$ Cancer. 2012; 106: 727-32. 
21. Betts G, Valentine H, Pritchard S, Swindell R, Williams V, Morgan S, et al. FGFR2, HER2 and cMet in gastric adenocarcinoma: detection, prognostic significance and assessment of downstream pathway activation. Virchows Arch. 2014;464:145-56.

22. Das K, Gunasegaran B, Tan IB, Deng N, Lim KH, Tan P. Mutually exclusive FGFR2, HER2, and KRAS gene amplifications in gastric cancer revealed by multicolour FISH. Cancer Lett. 2014; 353: 167-75.

23. Shoji H, Yamada Y, Okita N, Takashima A, Honma Y, Iwasa S, et al. Amplification of FGFR2 gene in patients with advanced gastric cancer receiving chemotherapy: prevalence and prognostic significance. Anticancer Res. 2015; 35: 5055-61.

24. Su X, Zhan P, Gavine PR, Morgan S, Womack C, Ni X, et al. FGFR2 amplification has prognostic significance in gastric cancer: results from a large international multicentre study. Br J Cancer. 2014; 110: 967-75.

25. Tokunaga R, Imamura Y, Nakamura K, Ishimoto T, Nakagawa S, Miyake K, et al. Fibroblast growth factor receptor 2 expression, but not its genetic amplification, is associated with tumor growth and worse survival in esophagogastric junction adenocarcinoma. Oncotarget. 2016; 7: 19748-61.

26. Seo S, Park SJ, Ryu MH, Park SR, Ryoo BY, Park YS, et al. Prognostic impact of fibroblast growth factor receptor 2 gene amplification in patients receiving fluoropyrimidine and platinum chemotherapy for metastatic and locally advanced unresectable gastric cancers. Oncotarget. 2017; 8: 33844-54.

27. Panic N, Leoncini E, de Belvis G, Ricciardi W, Boccia S. Evaluation of the endorsement of the preferred reporting items for systematic reviews and meta-analysis (PRISMA) statement on the quality of published systematic review and meta-analyses. PLoS One. 2013; 8: e83138.

28. Stang A. Critical evaluation of the Newcastle-Ottawa scale for the assessment of the quality of nonrandomized studies in meta-analyses. Eur J Epidemiol. 2010; 25: 603-5.

29. Wald NJ, Bestwick JP. Presentation of meta-analysis plots. J Med Screen. 2015; 22: $49-51$

30. Eagger M, Davey Smith G, Schneider M, Minder C. Bias in meta-analysis detected by a simple graphical test. BMJ. 1997; 315: 629-34.

31. Sterne JA, Sutton AJ, Ioannidis JP, Terrin N, Jones DR, Lau J, et al. Recommendations for examining and interpreting funnel plot asymmetry in meta-analyses of randomised controlled trials. BMJ. 2011; 343: d4002.

32. Turner N, Grose R. Fibroblast growth factor signaling: from development to cancer. Nat Rev Cancer. 2010; 10: 116-29.

33. Chang J, Liu X, Wang S, Zhang Z, Wu Z, Zhang X, et al. Prognostic value of FGFR gene amplification in patients with different types of cancer: a systematic review and meta-analysis. PLoS One. 2014; 9: e105524.

34. Liu G, Xiong D, Xiao R, Huang Z. Prognostic role of fibroblast growth factor receptor 2 in human solid tumors: A systematic review and meta-analysis. Tumour Biol. 2017;39:1010428317707424.

35. Kim HS, Kim JH, Jang HJ, Han B, Zang DY. Pathological and Prognostic Impacts of FGFR2 Overexpression in Gastric Cancer: A Meta-Analysis. J Cancer. 2019; 10: 20-7.

36. Kilgour E, Su X, Zhan P, Gavine P, Morgan S, Womack C, et al. Prevalence and prognostic significance of FGF receptor 2 (FGFR2) gene amplification in Caucasian and Korean gastric cancer cohorts. J Clin Oncol. 2012; 30 (Suppl 15): 4124.

37. Hierro C, Alsina M, Sánchez M, Serra V, Rodon J, Tabernero J. Targeting the fibroblast growth factor receptor 2 in gastric cancer: promise or pitfall? Ann Oncol. 2017; 28: 1207-16.

38. Gavine PR, Mooney L, Kilgour E, Thomas AP, Al-Kadhimi K, Beck S, et al. AZD4547: an orally bioavailable, potent, and selective inhibitor of the fibroblast growth factor receptor tyrosine kinase family. Cancer Res. 2012; 72: 2045-56.

39. Van Cutsem E, Bang YJ, Mansoor W, Petty RD, Chao Y, Cunningham D, et al. A randomized, open-label study of the efficacy and safety of AZD4547 monotherapy versus paclitaxel for the treatment of advanced gastric adenocarcinoma with FGFR2 polysomy or gene amplification. Ann Oncol. 2017; 28: 1316-24.

40. Wilson TR, Fridlyand J, Yan Y, Penuel E, Burton L, Chan E, et al. Widespread potential for growth-factor-driven resistance to anticancer kinase inhibitors. Nature. 2012; 487: 505-9.

41. Chang J, Wang S, Zhang Z, Liu X, Wu Z, Geng R, et al. Multiple receptor tyrosine kinase activation attenuates therapeutic efficacy of the fibroblast growth factor receptor 2 inhibitor AZD4547 in FGFR2 amplified gastric cancer. Oncotarget. 2015; 6: 2009-22. 